\title{
Reforma da previdência e trabalhista no Brasil: a democracia midiatizada no pós-impeachment de 2016
}

\author{
Rakel de Castro, José Shirley Pessoa do Nascimento \& Francisca Izabel A. dos Santos \\ Universidade CEUMA / Universidade do Estado do Rio Grande do Norte / Universidade CEUMA \\ E-mail: rakeldecastro@gmail.com/ jotashirley@gmail.com/ \\ izabelf.almeida@hotmail.com
}

\begin{abstract}
Resumo
A partir de 2013 o Brasil ressignificou seus momentos de políticas de uma maneira bem particular. Uma das consequências mais marcantes para a democracia do país foi a culminância do impeachment da então presidenta reeleita em 2014 com mais de 51 milhões de votos diretos, Dilma Rousseff, do Partido dos Trabalhadores. A nova gestão iniciada em 2015 foi marcada por intensas manifestações oposicionistas articuladas pelos partidos e políticos de direita com setores e instituições conservadoras e neoliberais como a Federação das Indústrias de São Paulo - FIESP e com largo apoio, numa alternância de agendamento e espiral do silêncio, de boa parte da mídia tradicional e corporativista brasileira. Paralelo a isso, o sitiamento do poder legislativo frente a uma das maiores investigações sobre corrupção (que se inicia dentro da Petrobrás e se expande para outros órgãos, inclusive no mercado imobiliário e na classe política) - a Lava Jato e a qual incluía o nome da maioria dos políticos brasileiros acabou gerando uma crise não só de representação política, mas dentro do próprio sistema político. A então presidenta cai em 2016 e assume o seu vice, Michel Temer, com a proposta de ser "o presidente das grandes reformas". Nesse contexto se inserem as propostas de reforma previdenciária (PEC 287) que entre outros aspectos muda a idade mínima requerida para a aposentadoria e a reforma trabalhista que dilui al-

guns direitos dos trabalhadores formais em nome de uma geração de emprego e renda do setor produtivo, como alternativa de sair da crise econômica. No entanto, o clima de insatisfação e polarização entre esquerda e direita não se acalmou depois do impeachment. E desde o início de 2017, quando essas duas reformas foram colocadas na pauta da mídia e do Congresso para votação, uma série de protestos, manifestações e greves reascenderam as forças de desejo de participação política direta. A esquerda, um tanto desestimulada pós-impeachment, viu na insatisfação popular frente às duas reformas, a possibilidade de união de uma grande parte da população em uma só causa: barrar o desmonte dos direitos dos trabalhadores. Assim, algumas manifestações e movimentos grevistas foram realizados no primeiro ano do Governo Temer, mas silenciado ou agendado de maneira distorcida pela grande mídia. Este artigo se propõe, portanto, a analisar a implantação das reformas da Previdência Social e da Legislação Trabalhista enquanto mecanismos de coesão popular em torno da insatisfação para com o novo governo de Michel Temer e como isso se relaciona diretamente com a cobertura midiática que se tem feito sobre as manifestações sociais depois do impeachment da presidenta Dilma. Qualitativamente se procederá a análise de discurso das principais notícias feitas em torno das reformas.
\end{abstract}

Data de submissão: 31/05/2017. Data de aprovação: 30/06/2017.

A Revista Estudos em Comunicação é financiada por Fundos FEDER através do Programa Operacional Factores de Competitividade - COMPETE e por Fundos Nacionais através da FCT - Fundação para a Ciência e a Tecnologia no âmbito do projeto Comunicação, Filosofia e Humanidades (LabCom.IFP) UID/CCI/00661/2013.
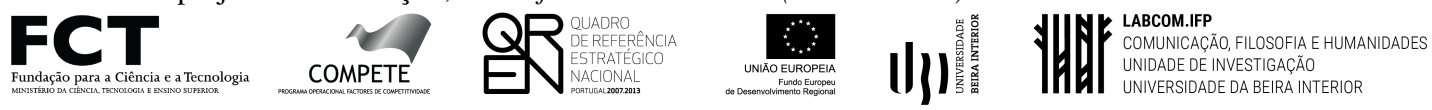
Palavras-chave: reforma trabalhista; reforma previdenciária; manifestações populares; mídia; pós-impeachment.

\begin{abstract}
From 2013 Brazil has given a new meaning to its policy in a very particular way. One of the most striking consequences for the country's democracy was the culmination of the impeachment of the twiceelected president (2010 and 2014) with more than 51 million direct votes, Dilma Rousseff, of the Partido dos Trabalhadores. The new government started in 2015 was marked by intense oppositionist manifestations articulated by right-wing parties and rightwing politicians, together with conservative and neoliberal sectors and institutions such as the Federação da Indústria de São Paulo (FIESP) and with broad support, in an alternation of scheduling and spiral of silence, of much of the traditional and corporatist Brazilian media. Parallel to this, the isolation of the legislative branch from one of the largest investigations into corruption (which begins within Petrobrás and expands to other institutions, including the real estate market and the political class) -the Lava Jato, which included the name of most Brazilian politicians ended up generating a crisis not only of political representation, but within the political system itself. President Dilma suffers a coup d'état and leaves the government in 2016. Assumes its deputy president, Michel Temer, with the proposal of being "the president of the great reforms". In this context are inserted the proposals for social security reform (PEC 287) that among other things changes the minimum

age required for retirement; and the labor reform that dilutes some rights of the formal workers in the name of a generation of employment and income of the productive sector, as an alternative to come out of the economic crisis. However, the mood of dissatisfaction and polarization between left and right did not calm down after impeachment. And since the beginning of 2017, when these two reforms were put on the agenda of the media and Congress for voting, a series of protests, demonstrations and strikes reasserted the forces of desire for direct political participation. The left, somewhat discouraged postimpeachment, saw the popular dissatisfaction with the two reforms, the possibility of union of a large part of the population in a single cause: stop the dismantling of workers' rights. Thus, some demonstrations and striking movements were carried out in the first year of the Temer Government, but silenced or scheduled in a distorted way by the mainstream media. This article therefore proposes to analyze the implementation of reforms of Social Security and Labor Legislation as mechanisms of popular cohesion around dissatisfaction with the new government of Michel Temer and how this relates directly to the media coverage that has made on social manifestations after the impeachment of President Dilma. Qualitatively it will proceed the analysis of discourse of the main news made around the reforms.
\end{abstract}

Keywords: labor reform; social security reform; popular manifestations; media; post-impeachment.

\title{
Considerações iniciais sobre o Impeachment de 2016 no Brasil
}

DENSAR o processo democrático brasileiro no primeiro ano pós-impeachment da presidenta 1 Dilma Roussef, ocorrido em agosto de 2016, é pensar também o processo de midiatização das decisões políticas sobre as quais participam governo e governados (ou dirigentes e dirigidos, nas palavras de Gramsci ${ }^{1}$ ) em um cenário de agendamento e espiral de silêncios contíguos.

\footnotetext{
1. 1984 .
} 
Não se pode dizer que somente agora o Brasil passa por efervescências políticas, materializadas pelas manifestações de 2013 e culminadas com um impeachment de uma presidente. O país sempre foi palco de revoluções, disputas por territórios e ideologias: leiam-se aqui os exemplos da Inconfidência Mineira, Conjuração Carioca, Revolução dos Alfaiates, Revolução Pernambucana, Guerra da Independência do Brasil, Confederação do Equador, Revolução Farroupilha entre tantos outros movimentos.

Entretanto foi somente a partir de 2013 que o papel da mídia mainstream (tanto em plataformas televisivas, impressas, radiofônicas e, agora de forma bem contundente, online) foi fundamental para se entender os processos de agendamentos e silenciamentos que reverberaram na democracia do país. Apenas em 2013, as manifestações iniciadas no âmbito popular e estudantil pela entidade Movimento Passe Livre - MPL (em ocasião do aumento das passagens do transporte público em algumas cidades do Brasil) tomaram algumas proporções incontroláveis pela própria entidade inicialmente organizadora. Do protesto dos estudantes contra 20 centavos estipulado pelo poder privado que detinha a concessão pública de operar os transportes públicos, passou-se a uma manifestação com adesão popular para além das comunidades estudantis e com reivindicações para a efetivação mais ampla de um Estado Social de Direito. Protestavam agora por mais educação, saúde, segurança.

Como essas pautas de reivindicações saíram do controle estudantil e não foram delimitadas pelos demais manifestantes, não se sabia especificamente o que se pedia na educação ou a quem se pedia isso (se ao governo municipal, estadual ou federal), por exemplo.

Foi então que outras entidades rapidamente se organizaram em torno do esvaziamento de organização das pautas reclamatórias. Partidos políticos começaram a patrocinar outras entidades como o Movimento Brasil Livre - MBL que, apesar de se dizer apartidário, organizou, depois que o MPL saiu de cena oficialmente quando conseguiu a redução das tarifas de ônibus em $2013^{2}$, várias manifestações patrocinas por partidos como PMDB, PSDB e $\mathrm{DEM}^{3}$ e por entidades como a Federação das Indústrias de São Paulo - FIESP. Para além disso, a mídia entrou no caso num processo amplo de apoio (Dijk, 2016) a este novo momento dos protestos, através de um agendamento contínuo, com chamadas de plantão ao vivo e com repórteres de renome nacional.

Desde então, os protestos mudaram o tom. A mídia também mudou o tom. O que antes havia sido veiculado como antidemocrático, ilegítimo e violento (Castro e Rocha, 2014); passou a ser amplamente publicado como movimento democrático, legítimo, que, ao invés de violento, sofria violência por parte da polícia e que livraria o país da corrupção. A pauta da corrupção estava sendo agendada a partir daquele momento. E nesse sentido, em meio a uma campanha eleitoral para presidente, o direcionamento para o "quem" (a quem se reivindicava) recebia da grande mídia a personificação e centralização no Governo Federal, nomeadamente a presidenta Dilma Roussef e o seu respectivo partido PT - Partidos dos trabalhadores (Dijk, 2016).

Outras plataformas que não a mídia televisiva, radiofônica e impressa também foram importantes nesse processo, como o surgimento e / ou fortalecimento de páginas no Facebook do \#VemPraRua (que fortalecia a pauta contra o governo do MBL e dos partidos de oposição, considerados

2. Haddad e Alckmin anunciam redução de tarifas do transporte público em SP (Estadão, 2013).

3. Lava Jato: confira a lista de políticos envolvidos em escândalo (IG, 2015). 
de direita) e, ao mesmo tempo, do \#MídiaNinja, auto intitulado como um processo de cobertura midiática independente (que fora bastante utilizado no fortalecimento dos discursos de apoio ao governo).

Ainda assim, Dilma se reelegeu em 2014, com mais de 51 milhões de votos, e inicia o segundo mandato em meio a este cenário turbulento que não acalmou, tampouco cessou em algum momento.

Em meio a isso, as decisões eram tomadas no Legislativo (Câmara dos deputados, inicialmente) e no campo investigativo da Polícia Federal e do Judiciário: eclode com muito mais força a midiatização da Operação Lava-Jato, primeiro no âmbito da Petrobras, depois estendida para o lócus de outras empresas não mais de economia mista, mas totalmente privadas. Ainda em 2015, sai na mídia uma primeira lista da empresa Odebrecht ${ }^{4}$ que denunciava esquemas de corrupção de inúmeros deputados, senadores e assessores políticos. A partir de então, a corrupção pautada pelo caminho mídia-ruas que hora abrangia a condição estatal apenas do executivo, escancaravase também nas portas e janelas do legislativo e do mercado privado. Empresas privadas estavam diretamente envolvidas no processo. Seguindo essa lógica, não daria mais para "demonizar" apenas o Estado pelos desvios de dinheiro e pagamento de propinas (valores de transações financeiras indevidas e não declaradas à Receita Federal), foi exatamente isso que, Segundo van Dijk (2016: online) a mídia fez.

Partidos e entidades continuavam organizando manifestações contra o governo e contra a corrupção. E mídia o que fazia? Midiatizava ao vivo, o dia todo, como uma espécie de convite em plantões especiais e edições ordinárias dedicadas exclusivamente à cobertura da tríada manifestação - corrupção - governo ${ }^{5}$, com o rosto, voz e assinatura de jornalistas "famosos" (os quais, teoricamente carregavam em sua imagem uma maior credibilidade).

Dilma Roussef então se exime de proceder a uma proteção política dos investigados na Lava Jato e o então Presidente da Câmara, Eduardo Cunha (PMDB) é indiciado pela Operação Lava Jato $^{6}$, em outubro de 2015. Como forma de retaliação ${ }^{7}$, ele aceita o processo de abertura de impeachment (em dois de dezembro de 2015) que foi à primeira votação na Câmara dos Deputados e transmitido ao vivo pelos principais canais de televisão do Brasil já em abril de 2016.

Durante os meses em que transcorreu o processo de investigação de crime de responsabilidade fiscal o qual teria sido cometido pela presidenta, as manifestações contra corrupção e governo continuavam: hora se batiam panelas no alto das janelas dos apartamentos de bairros onde morava boa parte da classe média (Chauí, 2000) brasileira (com direito a link ao vivo ou gravado em jornais televisivos); hora se organizava grandes manifestações animadas por cantores e artistas

4. Em março de 2015, Janot encaminhou uma lista para o STF pedindo a abertura de 21 inquéritos envolvendo 55 pessoas. O pedido daquela época foi feito com base na delação premiada do doleiro Alberto Youssef e do ex-diretor da Petrobras Paulo Roberto Costa (Exame, 2017).

5. (Cobertura ao vivo) Protestos a favor da Lava Jato e contra a corrupção (G1, 2016).

6. Moro recebe ação penal do STF, e Cunha vira réu da Lava Jato no PR $(\mathrm{G1}, 2016)$.

7. É possível se falar em retaliação, embora boa parte da mídia, à época, tenha construído um espiral de silêncio em torno da retaliação ou ter agendado isso de forma distorcida como previu Mauro Wolf (2005): Em retaliação ao PT, Cunha acolhe pedido de impeachment contra Dilma (Carta Capital, 2015); Eduardo Cunha autoriza abrir processo de impeachment de Dilma (G1, 2015); Cunha aceita pedido de impeachment contra Dilma. Presidente da Câmara descarta retaliação e diz que decisão é de 'natureza técnica' (O Globo, 2015). 
nacionais em trios elétricos. O MBL continuava arrogando para si a responsabilidade de limpar o país da lama da corrupção sendo apartidário, mesmo que para isso contasse com o apoio financeiro de alguns partidos. Esses mesmos partidos ${ }^{8}$ continuavam atuando na frente das câmeras enquanto na Câmara, mas nos bastidores enquanto na rua.

Uma vez aceito a abertura do processo de impeachment pelos deputados (com 367 votos a favor), as manifestações e a midiatizações delas não deram trégua. O processo democrático parecia ser pautado nas decisões políticas que os deputados investigados de corrupção pela justiça tomavam junto com a mídia e movimentos como o MBL.

O Estado social de direito reivindicado no início das manifestações perdera seu sentido e cedeu espaço para um Estado de exceção: grampos telefônicos ilegais são vazados pela própria justiça para a grande mídia, direitos e liberdades individuais são postos à prova e negligenciados. Gravações de conversas entre os investigados falam abertamente sobre obstruir as investigações e estancar a Lava Jato. No entanto, a mídia continuava agendando a tríade: manifestação - corrupção governo. Valia também agendar as investigações contra o ex-presidente Lula, ligado diretamente a então presidenta Dilma, pela sucessão na Presidência da República e pelo compartilhamento da mesma filiação partidária: PT.

A investigação segue então para o Senado e 31 de agosto de 2016, a presidenta cai. Sobe ao cargo máximo do executivo o então vice-presidente Michel Temer, com a promessa de austeridade e / ou "medidas impopulares" (em suas palavras: sabemos que o Estado não pode tudo fazer) ${ }^{9}$ como princípios norteadores do bem comum materializado na retirada no país da crise.

A pauta da crise agora é a principal. Já não se fala em manifestação contra corrupção de maneira sistemática. Outras denúncias voltam aparecer e mais uma vez, colocando a integridade do mercado em cheque: caso da JBS em que um dos presidentes da empresa, num acordo de delação premiada com a Procuradoria Geral da República grava até o próprio presidente Temer ${ }^{10}$ é redimensionada para "uma cassação do mandato do presidente Michel Temer (PMDB) teria potencial para jogar o país em outra crise e em um quadro de incógnitas" 11 (ainda que para isso esteja implícito agora a aceitação da corrupção).

É a partir dessas medidas de austeridades que se encontra a Reforma Trabalhista e Previdenciária, as quais são retratadas nesse artigo a partir de um recorte midiático e relacionadas com os aspectos da análise de discurso.

Dessa forma, elegeu-se o primeiro ano de governo Michel Temer, no pós-impeachment de 2016, como período de coleta de dados, feito através de e-clippings noticiosos do site G1 (da Rede Globo) em modulações com as notícias veiculadas por outras grandes redes de comunicação (em tradicionalidade de audiência e de captação de recursos publicitários, como SBT, Folha de São Paulo / Portal Uol etc.); por ter sido o período de votação das reformas austeras do Presidente Michel Temer, seguidas ou antecedidas das maiores manifestações populares no primeiro ano de

8. Áudios mostram que partidos financiaram MBL em atos pró-impeachment (Uol, 2016). Áudios revelam financiamento de MBL por partidos políticos (Extra Globo, 2016).

9. Leia íntegra do discurso de posse do presidente interino Michel Temer (Uol, 2016).

10. Dono da JBS gravou Temer dando aval para comprar silêncio de Cunha, diz jornal (G1, 2017). PF filma indicado por Temer recebendo propina: dono da JBS gravou conversa com presidente (O Globo, 2017).

11. Palavras de Gilmar Mendes (Supremo Tribunal Federal) em entrevista à Folha de São Paulo / Portal Uol (2017). 
seu Governo. Uma vez coletadas, as notícias foram categorizadas e tratadas discursivamente (Gill, 2002; Dijk, 2010) levando em consideração o "não dito / as entrelinhas / espiral do silêncio" e o "agendamento" (Wolf, 2005), enquanto processos contíguos que se relacionam com o fortalecimento ou enfraquecimento do movimento democrático brasileiro.

\section{O que a mídia conta sobre a reforma trabalhista do Governo Temer}

O projeto da reforma trabalhista aparece no discurso midiático como solução governista para a crise da economia brasileira e para o desemprego crescente no país, mas após a denúncia formal da Procuradoria Geral República contra o Presidente Temer, a reforma ganha papel como um meio de sobrevivência para o governo, que entra para a história como sendo o primeiro Presidente em exercício que virou réu comum ${ }^{12}$; junto com o ex-deputado Rodrigo Loures (PMBD-PR) por corrupção passiva, a partir da qual estão sendo investigadas as delações dos executivos da empresa JBS, em que o respectivo presidente Joesley Batista grava Temer em uma reunião, negociando 500 mil em propina. $\mathrm{O}$ ex-deputado peemedebista foi filmado carregando uma mala contendo $\mathrm{o}$ mesmo valor.

Em meio ao caos político, a reforma trabalhista ganhou força por causa do rumor social ${ }^{13}$ noticiado pela mídia tradicional, que reforça o discurso do governo ao apontar a necessidade do projeto como um estímulo à economia, sem uma opinião contrária sobre o assunto, e que acaba levando em seus telejornais, como no Jornal Hoje, da emissora Globo, reportagens de afirmação da reforma trabalhista, como no dia 12 de julho de $2017^{14}$, um dia após a aprovação. Foi ao ar uma matéria explicando as novas regras do projeto, o advogado e ex-Ministro do Trabalho, Almir Pazzianotto, validando o projeto com o seguinte argumento "há um excesso de interferência do Estado, [...] da Justiça do Trabalho e um excesso de legislação nas relações entre empregador e empregado."

No dia 11 de julho (terça-feira) a proposta passou no Senado em meio a protestos da oposição, que chegou a tomar a cadeira do presidente do Senado, Eunício Oliveira, provocando uma interrupção na votação por seis horas ${ }^{15}$, $\log$ o após houve a aprovação por 50 votos contra 26 e foi sancionada pelo presidente no dia 13 de julho (quinta-feira).

O texto base não mudou do que passou na Câmara dos Deputados, mas o Presidente Temer sinalizou que os pontos mais sensíveis da reforma seriam reavaliados e modificados através de Medidas Provisórias; entretanto, Rodrigo Maia, atual Presidente da Câmara, afirmou via Twitter que nenhuma proposta que visa modificar a lei será aceita pela Câmara.

O texto apresentou proposta para flexibilizar a contratação de empregados, mudando pontos da legislação como férias, jornada de trabalho, plano de carreira, remuneração e regulamenta

12. Temer é denunciado por corrupção e se torna primeiro presidente a responder por crime durante mandato (El País, 2017)

13. A partir do momento em que o rumor social é incluído no acontecimento, a mídia torna-se partidária nesse agendamento. É, ao mesmo tempo, externa e interna a um acontecimento ao qual atribui limites por seu próprio discurso. (Barreto, 2006: 18)

14. https://globoplay.globo.com/v/6002815/

15. www1.folha.uol.com.br/mercado/2017/07/1900394-apos-6-horas-de-suspensao-senado-retoma-sessao-para-vot ar-reforma-trabalhista.shtml 
novas modalidades como home office e trabalho intermitente. As polêmicas envolvendo a proposta de lei que modifica determinações básicas e que protegem o trabalhador dividiu a opinião das Instituições e da população.

Como por exemplo, as férias podem fracionadas em até três períodos, mediante negociação, contando que um dos períodos seja de 15 dias corridos. Antes, as férias poderiam ser fracionadas em até dois períodos, sendo que um deles não pode ser inferior a 10 dias e existia a possiblidade de 1/3 do período ser pago em forma de abono. O ponto mais polêmico da discussão é a questão da negociação, que agora os acordos coletivos e convenções, podem prevalecer sobre a legislação. Os sindicatos e as empresas podem negociar condições de trabalho diferentes das previstas em lei, mas não necessariamente beneficia o trabalhador. Acordos individualizados de livre negociação para empregados com instrução de nível superior e salário mensal igual ou superior a duas vezes o limite máximo dos benefícios do INSS, serão priorizados sobre o coletivo. Antes, as convenções e os acordos coletivos podem estabelecer condições de trabalho diferentes das previstas na legislação apenas se beneficiar o trabalhador a um patamar superior ao que estiver previsto em lei.

Outro ponto polêmico é sobre a demissão do trabalhador, que antes da reforma o empregado não tinha direito à multa de $40 \%$ sobre o saldo do FGTS nem à retirada do fundo. O trabalhador tem direito ao aviso prévio sobre a demissão de 30 dias de antecedência ou pagar o salário referente ao mês sem que o funcionário precise trabalhar e caso for demitido, terá o direito do seguro-desemprego. Agora, o contrato poderá ser extinto em comum acordo, com o pagamento de metade do aviso prévio e metade da multa de $40 \%$ sobre o saldo do FGTS e o empregado poderá movimentar $80 \%$ do valor depositado pela empresa na conta do Fundo de Garantida por Tempo de Serviço (FGTS), mas não terá direito ao seguro-desemprego.

A Reforma Trabalhista se sustenta em um conjunto de pautas que faz parte das decisões políticas econômicas do governo, sendo elas: i) reestruturação produtiva, mercantilização do trabalho humano e fragmentação da solidariedade de classe, ii) desregulamentação financeira e laboral, iii) hegemonização ideológica neoliberal pautada no individualismo e na competitividade.

Na pesquisa realizada pelo site do Senado ${ }^{16}$ sobre a Reforma Trabalhista, 172.168 pessoas votaram contra a matéria, contra 16.791 votos a favor do projeto. Isso mostra, em boa medida, que a aprovação da modificação dos direitos trabalhistas foi à revelia de uma parcela significativa da opinião pública, ou seja, contra os próprios cidadãos. A falta de apresentação de argumentos contrários a opinião do governo na mídia tradicional, criou-se uma falsa sensação de concordância geral sobre a Reforma Trabalhista.

A votação da Conselho de Constituição e Justiça que decidiria se o processo contra o presidente Temer seguiria para o Supremo Tribunal Federal aconteceu um dia antes da ida da proposta governista ao Senado, em meio a promessas por parte do governo em fazer repasses milionários as bases aliadas para as suas pastas a fim de que o relatório não fosse aprovado no Conselho legislativo. Uma das Instituições que ficou contra o projeto, foi o próprio Ministério do Trabalho ${ }^{17}$. O MP apresentou um relatório sobre a matéria do governo e apontou que o projeto além de ser considerado inconstitucional, achou doze pontos que fere os direitos trabalhistas diretamente e que

16. www12.senado.leg.br/ecidadania/visualizacaomateria?id=129049

17. www.valor.com.br/politica/4940558/mp-do-trabalho-pede-rejeicao-do-relatorio-da-reforma-trabalhista 
violam os princípios da dignidade humana e da proteção social do trabalho ${ }^{18}$, criando margem para brechas e que podem ameaçar até o salário mínimo.

Em números passados pelo Ministério do Trabalho, no ano de 2016, as varas trabalhistas receberam 2,66 milhões de casos ${ }^{19}$ envolvendo insalubridade, pagamento de horas extras e cobranças de verbas rescisórias. A pergunta ressoante que ainda perdura em alguns brasileiros diante de um futuro político e econômico incerto para 2018 é: como o enfraquecimento da seguridade do trabalho vai trazer de volta a estabilidade financeira das classes mais baixas da sociedade brasileira?

A popularidade do atual Presidente da República, Michel Temer, caiu 75\% e apenas 4\% consideram o governo como bom ou ótimo ${ }^{20}$. O projeto apareceu em um momento turbulento no cenário político e econômico, o Brasil vem atravessando o ano de 2017 em um mar de denúncias de corrupção envolvendo políticos e grandes empresas, como JBS, Odebrecht, OAS e Petrobrás. Diante das denúncias na Lava Jato e na abertura do processo contra Temer já arquivado pelo Senado no último dia, a Reforma Trabalhista é uma vitória significativa para o governo que procura sobreviver a qualquer custo.

\section{A reforma previdenciária e a insatisfação popular midiatizada}

Diante do atual contexto político brasileiro, o governo federal busca reafirmar poder junto a base aliada através de propostas que impactam diretamente nas rotinas de trabalho da sociedade, alegando ser alternativas que permitam equilibrar a economia do país. No entanto, há uma forte repulsa da população para com essas mudanças, como as já aprovadas lei da terceirização e a reforma trabalhista, e agora a reforma previdenciária que vem sendo tramitada através da Proposta de Ementa Constitucional 287/2016.

O poder executivo apresentou a PEC 287/287 através do Ministro da Fazendo Henrique Meirelles para apreciação da Câmara dos Deputados no dia 05 de dezembro de 2016, uma Proposta de Ementa Constitucional que sugere uma reforma na previdência social. A quinta PEC que modifica o sistema previdenciário brasileiro a partir da Constituição de 1988, traz junto com o discurso do Governo Temer a hipótese de um aumento significativo na expectativa de vida dos brasileiros, o que consequentemente faria com que o Brasil tivesse maior número de pessoas contribuindo por menos tempo e recebendo aposentadoria por mais tempo; fato que desequilibraria o recolhimento do INSS e geraria um déficit na previdência social, o famoso "rombo" alegado pelo Governo Federal.

Uma das principais mudanças está a estipulação de uma nova idade mínima para aposentadoria, que seria de 65 anos tanto para homens quanto para mulheres em todas as classes trabalhistas, incluindo servidores públicos, agricultores e professores; uma vez que esses dois últimos possuíam um regime especial para aposentadoria. Agora, passam a se enquadrar no mesmo regime geral, alterando os artigos 37, 40, 109, 149, 167, 195, 201 e 203 da Constituição Federal e modificando regras de transição e valor do benefício.

18. http://reporterbrasil.org.br/2017/07/por-que-a-reforma-trabalhista-e-inconstitucional/

19. http://economia.estadao.com.br/noticias/geral,acoes-trabalhistas-crescem-e-tst-preve-3-milhoes-de-processos-e $\mathrm{m}-2016,10000050140$

20. www.bbc.com/portuguese/brasil-39713534 
O texto da PEC, sugerindo reformas na previdência, gerou negativo impacto na opinião pública desde que foi entregue à Câmara, constatada através de manifestos populares organizados por diversas classes trabalhistas, estes materializados de forma mais intensa no mês de março de 2017 por meio de duas grandes paralizações. Os principais grupos articuladores dos manifestos foram a Confederação Nacional dos Trabalhadores da Educação (CNTE) e a Central única dos Trabalhadores (CUT). Demais órgão também convocaram seus sindicados filiados, como a Nova Central Sindical dos Trabalhadores (NCST) e a Central dos Trabalhadores do Brasil (CTB).

No $33^{\circ}$ Congresso Nacional da CNTE, ocorrido de 12 a 15 de janeiro de 2017, foi deliberado a deflagração de GREVE NACIONAL DA EDUCAÇÃO, a partir de 15 de março. Inúmeras categorias em todo país também aderiram a uma paralisação nessa data (Confederação Nacional dos Trabalhadores da Educação, 2017).

A CUT, principal organização que reúne boa parte dos sindicatos brasileiros, federações e confederações em prol dos direitos dos trabalhadores, anunciou, através do atual presidente nacional da CUT Vagner Freitas, em 21 de fevereiro, também uma paralisação afim de impedir a reforma na previdência no dia 15 de março (Central Única dos Trabalhadores, 2017), data da primeira votação na Câmara dos Deputados.

Assim se organizaram no país em manifestações contra a reforma da previdência conforme mostra a Tabela 01: 
Tabela 1. Número de manifestantes em 15 de março por capital brasileira

\begin{tabular}{|c|c|}
\hline Capital/Sigla do Estado & Número estimado de participantes \\
\hline Rio Branco/AC & 7 mil pessoas \\
\hline Maceió/AL & 8 mil pessoas \\
\hline Manaus/AM & 5 mil \\
\hline Macapá/AP & Dados não divulgados \\
\hline Salvador/BA & 10 mil \\
\hline Fortaleza/CE & $50 \mathrm{mil}$ \\
\hline Brasília/DF & 10 mil \\
\hline Vitória/ES & 3 mil \\
\hline Goiânia/GO & 25 mil \\
\hline São Luís/MA & 3 mil \\
\hline Cuiabá/MT & 6 mil \\
\hline Campo Grande/MS & 20 mil \\
\hline Belo Horizonte/MG & $150 \mathrm{mil}$ \\
\hline Belém/PA & 5 mil \\
\hline João Pessoa/PB & 3 mil \\
\hline Curitiba/PR & 60 mil \\
\hline Recife/PE & 40 mil \\
\hline Teresina/PI & Dados não divulgados \\
\hline Rio de Janeiro/RJ & $100 \mathrm{mil}$ \\
\hline Natal/RN & $20 \mathrm{mil}$ \\
\hline Porto Alegre/RS & $10 \mathrm{mil}$ \\
\hline Porto Velho/RO & 5 mil \\
\hline Boa Vista/RR & 5 mil \\
\hline São Paulo/SP & 200 mil \\
\hline Florianópolis/SC & Dados não divulgados \\
\hline Aracajú/SE & 7 mil \\
\hline Palma/TO & $2,5 \mathrm{mil}$ \\
\hline TOTAL & 754,5 mil pessoas \\
\hline
\end{tabular}

O dia 15 de março foi, portanto, a data em que ocorreu um dos maiores manifestos em todo país, considerado um marco nacional pelos organizadores e negligenciado pela mídia mainstream. Segundo o Brasil de Fato (2017) foi registrado cerca de 1 milhão de manifestantes nos grandes centros das capitais brasileiras, transcorrendo protestos em estradas, rodovias, escolas, dentre outras partições públicas. Destaca-se em meios a esses atos, uma ocupação no prédio do Ministério da Fazenda, com o registro de cerca de dez mil manifestantes, e outra ação realizada em frente ao Congresso Nacional, na qual os manifestantes espalharam cruzes simbolizando a morte dos trabalhadores que não conseguiriam se aposentar (G1, 2017). Mesmo noticiando o movimento ao longo do dia, as grandes empresas de mídias eletrônica e impressa do Brasil, como Globo, Re- 
cord e SBT não fizeram a cobertura de forma semelhante à cobertura pre-impeachment. $\mathrm{O}$ tom, a credibilidade dos comunicadores e a periodicidade eram outras.

De forma semelhante, no dia 28 de abril de 2017, realizou-se a maior greve geral dos últimos vinte anos no Brasil. No entanto, a mídia que falou timidamente sobre todos os manifestos pós-impeachment, resolveu noticiar o do dia 28 , já que este teve especificamente uma adesão peculiarmente grandiosa de muitos setores sociais; inclusive das áreas comerciais e públicas. Mas a construção noticiosa se pautou não como greve geral, mas como um dia manifestação prejudicial para economia em crise, em virtude que se paralisava as atividades em um dia útil da semana, numa sexta-feira. Além disso, o foco nas confusões com a polícia, na fechação das estradas e dos aeroportos funcionou como uma tentativa de deslegitimar o movimento grevista.

Em reforço contra a proposta, algumas câmaras municipais moveram moção de repúdio para o congresso, como as cidades de Minas Gerais. Petições online também serviram para reforçar o tom de insatisfação popular contra a reforma da previdência como a realizada na plataforma Avaaz (2017), com um registro de mais de trezentas mil assinaturas coletadas.

Em resposta ao descontentamento popular que se relaciona diretamente com a rejeição do Governo Temer, este lançou uma campanha publicitária na TV, na qual faz comparativos com outras mudanças ocorridas no país nas últimas décadas, chegando a afirmar discursivamente que, se não houver a reforma, "o Brasil vai quebrar".

Ainda se utilizando muito fortemente da mídia televisiva, Michel Temer chegou a conversar com o apresentador e empresário Sílvio Santos pedindo-lhe para usar de sua influência para que apoiassem também a reforma trabalhista. O SBT então passou a transmitir comerciais curtos em sua grade, repassando mensagens de alerta sobre a importância em aprovar a reforma. Nesse contexto, a base parlamentar do governo buscou apoio também dentro da classe empresarial; inclusive, fazendo-a aparecer na mídia em forte apoio à proposta governista.

Somem-se a estes fatos, alguns outros que agravam ainda mais a crise de credibilidade da democracia representativa no país, como o episódio em que o deputado Alceu Moreira (PMDB / RS), relator da PEC 287/16, em sessão na Câmara, referiu-se aos aposentados como "vagabundos", ao dizer que "o tempo da "vagabundização' acabou", reiterando que "vagabundo remunerado não receberá". Tal dito foi relacionado pela ala oposicionista ao governo com uma fala do ex-presidente da República, Fernando Henrique Cardoso (FHC), durante a reforma previdenciária de 1998, quando pediu para que os brasileiros não se aposentassem antes dos 50 anos de idade para não se tornarem "vagabundos". Fato que gerou ainda mais controvérsia e insatisfação popular.

\section{O que isso tem a ver com a democracia}

Pensar que as técnicas de agendamento e espiral de silêncio midiático podem funcionar como processos de distorções sistemáticas da comunicação (Wolf, 2005) é considerar também o quanto esses mecanismo podem funcionar como instrumento de dominação abusiva discursiva, como previu Van Dijk (2012).

Quando a G1 decide noticiar a maior greve geral ocorridas nos últimos 20 anos do Brasil sem mencionar nem o nome de greve, mas de manifestação, evidencia a preocupação da mídia mainstream em negar a legitimidade e o poder do trabalhador (legalmente investido) de fazer 
greve. Parece ser mais saudável para as bases governistas e às reformas de austeridade que o movimento grevista do dia 28 de abril de 2017 seja chamado de manifestação. Assim poder-se-ia inferir falta no ponto trabalhista do trabalhador que faltasse o emprego para se apoiar o movimento.

Assim o G1, que representa também muito fortemente a linda editorial da Rede Globo e, a partir do qual, oferece significo indício de como a cobertura televisiva e radiofônica fora feita, comportou-se jornalisticamente enviesado quando da midiatização dos processos de tentativa de participação direta democrática de uma grande parcela da população brasileira.

Da cobertura deslegitimadora do discurso estudantil por " 0,20 centavos", passando pelo agendamento que incorporava o discurso da classe média por um Estado Social de Direito (saúde, educação e segurança) e ainda por um Estado sem corrupção; a grande mídia silenciou quando as manifestações se fizeram presentes no governo pós-impeachment e / ou voltou a agendá-las de maneira sistematicamente distorcidas, deslegitimando-as enquanto movimento de "vagabundos", violentas, baderneiras e antidemocráticas (muito semelhante quando ocorreram as primeiras manifestações em 2013 contra o aumento das passagens de ônibus e trem) que só prejudicavam ainda mais o cenário de crise econômica. O discurso da mídia mudou em 5 anos sobre as manifestações populares para se adequar a quem protagonizava tais manifestações; mais para se adequar a que interesse governista era mais interessante a ela. Repercutiu e midiatizou o interesse de uma classe dominante, fazendo parecer que aquilo era bom para todos (Gramsci, 1984), era de interesse de todos sair da crise por exemplo, mesmo que para isso direitos trabalhistas e previdenciários fossem retirados, inclusive flexibilizando o entendimento e fiscalização do "trabalho escravo".

Do processo contra os 0,20 centados, aos discursos por educação, saúde, segunrança, contra a corrupção e para salvar o Brasil da crise, serviram para se analisar que a democracia não se efetiva somente nas instâncias políticas oficiais como o Legislativo e o Executivo. Paulo Serra (2015) vai afirmar que no desenrolar da relação entre mídia e política, as mídias não se reduzem a meros meios nem os jornalistas a mensageiros - uns e outros transformaram-se em agentes políticos de primeiro plano. Não no sentido em que efetuam a defesa de uma ideologia ou de uma corrente política (o que também podem fazer), mas no sentido em que as mídias podem se tornar um verdadeiro parlamento do nosso tempo. Com efeito, é nas mídias, e não já só no Parlamento, que as discussões políticas não só se iniciam, mas também se tornam decisivas - no duplo sentido de ganharem importância, de levarem a uma decisão ou de calarem o assunto no debate e, consequentemente, no âmbito de tomada de atitudes.

Acredita-se, portanto, que o jornalismo tem um forte poder não só oferecer credibilidade aos fatos, mas de legitimar verdades e construir socialmente a realidade (Corcuff, 2001). Pensar, então, como isso tem acontecido no Brasil pós-impeachment 2016, é uma possibilidade de verificação de como a ideia de democracia tem se forjado em meio a essas duas instâncias: a cobertura da tradicional mídia de um lado e o desejo de participação política frente às reformas trabalhistas e previdenciárias do outro. 


\section{Referências}

(2017, julho 12). Especialistas falam sobre as mudanças na vida do trabalhador e da empresa. Jornal Hoje. Emissora Globo. Globo. Recuperado em 14 julho, 2017, de https://globoplay.globo $. \mathrm{com} / \mathrm{v} / 6002815 /$.

(2017, abril 17). MP do trabalho pede rejeição do relatório da reforma trabalhista. Site Valor econômico. Valor. Recuperado em 15 julho, 2017, de http://www.valor.com.br/politica/4940 558/mp-do-trabalho-pede-rejeicao-do-relatorio-da-reforma-trabalhista.

(2017, maio 17). Dono da JBS gravou Temer dando aval para comprar silêncio de Cunha, diz jornal. Globo. Recuperado em 20 outubro, 2017, de https://g1.globo.com/politica/noticia/donoda-jbs-gravou-temer-dando-autorizacao-para-comprar-silencio-de-cunha-diz-jornal.ghtml.

(2016 , maio 27). Áudios revelam financiamento de MBL por partidos políticos. Globo. Recuperado em 15 outubro, 2017, de https://extra.globo.com/noticias/brasil/audios-revelamfinanciamento-de-mbl-por-partidos-politicos-diz-portal-19384868.html.

(2016, maio 12). Leia íntegra do discurso de posse do presidente interino Michel Temer. UOL. Recuperado em 20 outubro, 2017, de www1.folha.uol.com.br/poder/2016/05/1770780-leiaintegra-do-discurso-de-posse-do-presidente-interino-michel-temer.shtml.

(2015, março 6). Lava Jato: confira a lista de políticos envolvidos em escândalo. IG. Recuperado em 20 outubro, 2017, de http://ultimosegundo.ig.com.br/politica/operacao-lava-jato/201503-06/lava-jato-confira-a-lista-de-politicos-envolvidos-em-escandalo.html.

(2015, dezembro 2). Em retaliação ao PT, Cunha acolhe pedido de impeachment contra Dilma. Carta Capital. Recuperado em 10 outubro, 2017, de www.cartacapital.com.br/politica/emretaliacao-ao-pt-cunha-acolhe-pedido-de-impeachment-contra-dilma-5647.html.

(n.d). Protestos a favor da Lava Jato e contra a corrupção. Globo. Recuperado em 19 outubro, 2017, de http://g1.globo.com/politica/ao-vivo/2016/manifestacoes-no-brasil.html.

Barreto, E. (2006). Jornalismo e política: a construção do poder. Estudos em Jornalismo e Mídia, 3(1), 11-22. Recuperado em 14 julho, 2017, de https://periodicos.ufsc.br/index.php/jornalism o/article/view/2238.

Benites, A. (2017, junho 27). Temer é denunciado por corrupção e se torna primeiro presidente a responder por crime durante mandato. El País. Recuperado em 20 outubro, 2017, de https://brasil.elpais.com/brasil/2017/06/26/politica/1498485882_380890.html.

Bergano, M. (2017, junho 12). Cassação lançaria o país em quadro de incógnita, afirma Gilmar Mendes. UOL. Recuperado em 20 outubro, 2017, de www1.folha.uol.com.br/poder/2017/06/ 1892133-cassacao-lancaria-o-pais-em-quadro-de-incognita-afirma-gilmar-mendes.shtml.

Chauí, M. (2000). Convite à filosofia. São Paulo: Ed. Ática.

Corcuff, P. (2001). As novas sociologias: construções da realidade social. Rio de Mouro: Sintra.

Costa, C. (2017, abril 26). Aprovação de Temer cai a 10\% e 92\% da população veem país no rumo errado. BBC Brasil. Recuperado em 15 julho, 2017, de www.bbc.com/portuguese/brasil39713534. 
Dijk, T. (2016, dezembro 19). Como a Rede Globo manipulou o impeachment da presidente do Brasil, Dilma Rousseff. Carta Maior. São Paulo. Recuperado em 21 dezembro, 2017, de http://cartamaior.com.br/?/Editoria/Midia/Como-a-Rede-Globo-manipulou-o-impeachment -da-presidente-do-Brasil-Dilma-Rousseff/12/37490.

Dijk, T. (2010). Discurso e poder. (trad. J. Hoffnagel, A. R. Vieira, L. Mozdzenski, B. G. Bezerra, R. Castro \& K. Falcone). São Paulo: Contexto.

Duailibi, J. \& Gallo, F. (2013, junho 19). Haddad e Alckmin anunciam redução de tarifas do transporte público em SP. Estadão. Recuperado em 16 outubro, 2017, de http://politica.estadao.co $\mathrm{m}$. br/noticias/geral,haddad-e-alckmin-anunciam-reducao-de-tarifas-do-transporte-publico-e m-sp, 1044416 .

Fernandes, T. \& Alegretti, L. (2017, julho 11). Após 6 horas de suspensão, Senado retoma sessão para votar reforma trabalhista. UOL. Recuperado em 17 agosto, 2017, em www1.folha.uol.co m.br/mercado/2017/07/1900394-apos-6-horas-de-suspensao-senado-retoma-sessao-para-vot ar-reforma-trabalhista.shtml.

Gil, R. (2002). Análise de discurso. In M. W. Bauer \& G. Gaskell (orgs.), Pesquisa qualitativa com texto: imagem e som: um manual prático. (trad. P. A. Guareschi). Petrópolis: Vozes.

Gois, C. de \& Fernandes, L. (2015 b). Cunha aceita pedido de impeachment contra Dilma. Presidente da Câmara descarta retaliação e diz que decisão é de 'natureza técnica'. Globo. Recuperado em 18 outubro, 2017, de https://oglobo.globo.com/brasil/cunha-aceita-pedidode-impeachment-contra-dilma-18202665.

Gramsci, A. (1984). Maquiavel, a política e o estado moderno. Rio de Janeiro: Civilização Brasileira.

Jardim, L. (2017 , maio 17). PF filma indicado por Temer recebendo propina: dono da JBS gravou conversa com presidente. Globo. Recuperado em 20 outubro, 2017, de https://oglobo.globo.c om/brasil/pf-filma-indicado-por-temer-recebendo-propina-21353989.

Lopes, P. \& Segalla, V. (2016, maio 27). Áudios mostram que partidos financiaram MBL em atos pró-impeachment. UOL. Recuperado em 20 outubro, 2017, de https://noticias.uol.com.br/pol itica/ultimas-noticias/2016/05/27/maquina-de-partidos-foi-utilizada-em-atos-pro-impeachm ent-diz-lider-do-mbl.htm.

Magalhães, A. (2017, julho 10). Por que a reforma trabalhista é inconstitucional? Repórter Brasil. Reporter Brasil. Recuperado em 15 julho, 2017, de http://reporterbrasil.org.br/2017/07/porque-a-reforma-trabalhista-e-inconstitucional/.

Mendonça, R. N. (2017, abril 20). Por que a reforma trabalhista é tão urgente para a direita brasileira?. Brasil de Fato. Recuperado em 19 agosto, 2017, de www.brasildefato.com.br/2017/04 /20/artigo-or-por-que-a-reforma-trabalhista-e-tao-urgente-para-a-direita-brasileira/.

Passarinho, N. (2015 a). Eduardo Cunha autoriza abrir processo de impeachment de Dilma. Globo. Recuperado em 18 de outubro, 2017, de http://g1.globo.com/politica/noticia/2015/12/eduard o-cunha-informa-que-autorizou-processo-de-impeachment-de-dilma.html. 
Santos, B. F. (2017, abril 12). Dois anos depois, o que aconteceu com a primeira lista de Janot. Exame. Recuperado em 15 outubro, 2017 de https://exame.abril.com.br/brasil/o-queaconteceu-com-os-politicos-da-primeira-lista-de-janot/\#.

Senado Federal (n.d). Consulta pública sobre a reforma trabalhista. Recuperado em 15 julho, 2017, de www12.senado.leg.br/ecidadania/visualizacaomateria?id=129049.

Siqueira, C. (2016, abril 19). Câmara autoriza instauração de processo de impeachment de Dilma com 367 votos a favor e 137 contra. Câmara dos Deputados. Recuperado em 10 outubro, 2017, de www2.camara.leg.br/camaranoticias/noticias/POLITICA/507325-CAMARAAUTORIZA-INSTAURACAO-DE-PROCESSO-DE-IMPEACHMENT-DE-DILMA-COM367-VOTOS-A-FAVOR-E-137-CONTRA.html .

Vianna, J.; Nunes, S. \& Kaniak, T. (2016, outubro 13). Moro recebe ação penal do STF, e Cunha vira réu da Lava Jato no PR. Globo. Recuperado em 19 outubro, 2017, de http://g1.globo.com /pr/parana/noticia/2016/10/moro-recebe-acao-do-stf-e-cunha-vira-reu-da-lava-jato-no-paran a.html.

Weterman, D. \& Neris, F. (2016, maio 16). Ações trabalhistas crescem e TST prevê 3 milhões de processos em 2016. Estadão. Recuperado em 15 julho, 2017, de http://economia.estadao.co $\mathrm{m} . \mathrm{br} /$ noticias/geral,acoes-trabalhistas-crescem-e-tst-preve-3-milhoes-de-processos-em-2016 ,10000050140. 